ORIGINAL ARTICLE

\title{
Characterization of cerebral glucose dynamics in vivo with a four-state conformational model of transport at the blood-brain barrier
}

\author{
João M. N. Duarte*'† and Rolf Gruetter*†† \\ *Laboratory for Lunctional Metabolic Imaging, École Polytechnique Fédérale de Lausanne, Lausanne, \\ Switzerland \\ $\dagger$ Department of Radiology, University of Lausanne, Lausanne, Switzerland \\ $\ddagger$ Department of Radiology, University of Geneva, Geneva, Switzerland
}

\begin{abstract}
Determination of brain glucose transport kinetics in vivo at steady-state typically does not allow distinguishing apparent maximum transport rate $\left(T_{\max }\right)$ from cerebral consumption rate. Using a four-state conformational model of glucose transport, we show that simultaneous dynamic measurement of brain and plasma glucose concentrations provide enough information for independent and reliable determination of the two rates. In addition, although dynamic glucose homeostasis can be described with a reversible Michaelis-Menten model, which is implicit to the large iso-inhibition constant $\left(K_{\mathrm{ii}}\right)$ relative to physiological brain glucose content, we found that the apparent affinity constant $\left(K_{\mathrm{t}}\right)$ was better determined with the four-state conformational model of glucose transport
\end{abstract}

than with any of the other models tested. Furthermore, we confirmed the utility of the present method to determine glucose transport and consumption by analysing the modulation of both glucose transport and consumption by anaesthesia conditions that modify cerebral activity. In particular, deep thiopental anaesthesia caused a significant reduction of both $T_{\max }$ and cerebral metabolic rate for glucose consumption. In conclusion, dynamic measurement of brain glucose in vivo in function of plasma glucose allows robust determination of both glucose uptake and consumption kinetics.

Keywords: blood-brain barrier, $\mathrm{CMR}_{\text {glc, }}$ glucose transport, GLUT, mathematical modelling, nuclear magnetic resonance. J. Neurochem. (2012) 121, 396-406.
Maintaining normal brain function requires glucose that is supplied from blood through facilitative glucose carrier proteins located at the blood-brain barrier (BBB), namely glucose transporter type 1 (GLUT1; Pardridge et al. 1990; Simpson et al. 2007). Over the two last decades, noninvasive in vivo NMR techniques have been used to measure glucose concentration and its transport and metabolism in the brain of both humans (e.g. Gruetter et al. 1996, 1998, 2001; Shestov et al. 2011) and rodents (e.g. Choi et al. 2002; Duarte et al. 2009a, 2011a; Lei et al. 2010). For that, mathematical models of glucose transport across the BBB were initially based on irreversible Michaelis-Menten (MM) kinetics (e.g. Lund-Andersen 1979; Mason et al. 1992; Gruetter et al. 1996). These were abandoned because in certain experimental conditions brain glucose concentrations on the order of the $K_{\mathrm{M}}$ of glucose carriers were observed, and a reversible MM kinetics was thus introduced to describe brain glucose transport as observed in vivo namely by NMR spectroscopy (Cunningham et al. 1986; Gruetter et al. 1998). However, some studies found that such kinetics failed to determine the apparent affinity constant of glucose transport $K_{\mathrm{t}}$ (Seaquist et al. 2001; Choi et al. 2002; Lei and Gruetter 2006; Shestov et al. 2011), which often largely diverged from the $K_{\mathrm{M}}$ for glucose transport determined in vitro (e.g.

Received October 24, 2011; revised manuscript received January 4, 2012; accepted February 07, 2012.

Address correspondence and reprint requests to João M. N. Duarte, EPFL SB IPMC LIFMET, Station 6 (Bâtiment CH), CH-1015 Lausanne, Switzerland. E-mail: joao.duarte@epfl.ch

Abbreviations used: $\mathrm{BBB}$, blood-brain barrier; $\mathrm{CMR}_{\mathrm{glc}}$, cerebral metabolic rate for glucose consumption; CRLB, Cramér-Rao lower bound; GLUT1, glucose transporter type 1; $K_{\mathrm{ii}}$, apparent iso-inhibition constant; $K_{\mathrm{M}}{ }^{\mathrm{HK}}$, apparent Michaelis constant of hexokinase; $K_{\mathrm{t}}$, apparent affinity constant of glucose transport; MM, Michaelis-Menten; $T_{\max }$, apparent maximum transport rate; $V_{\max } \mathrm{HK}$, apparent maximum rate of hexokinase; VOI volume of interest. 
Gould et al. 1991; Lee et al. 1997). Reversible MM kinetics does not consider iso-inhibition or trans-acceleration, in contrast to the conformational four-state exchange kinetic model of simple solute carriers that has been proposed to describe glucose transport across the BBB (Barros et al. 2007; Duarte et al. 2009b).

Glucose transport kinetics as measured in vivo by ${ }^{1} \mathrm{H}$ NMR spectroscopy has been mostly determined under steady-state conditions (Gruetter et al. 1998; Seaquist et al. 2001; Choi et al. 2002; Lei and Gruetter 2006; Lei et al. 2010). However, steady-state transport measurement from brain glucose $\left(G_{\text {brain }}\right)$ content did not allow determining the maximum transport rate separately from the glucose consumption rate. Consequently, a ratio between the two was estimated and often a constant cerebral metabolic rate of glucose $\left(\mathrm{CMR}_{\mathrm{glc}}\right)$ has been assumed to allow determination of an apparent maximum transport rate $\left(T_{\max }\right)$ (e.g. Gruetter et al. 1998; Duarte et al. 2009a; Lei et al. 2010). Gruetter et al. (1996) determined glucose transport kinetics from changes in brain glucose content measured using ${ }^{1} \mathrm{H}$ NMR difference spectroscopy after a rapid increase in plasma glucose concentration. This method had the advantage of providing a dynamic measure of $G_{\text {brain, which allowed the }}$ determination of both $T_{\max }$ and $\mathrm{CMR}_{\mathrm{glc}}$ using, at that time, an irreversible MM kinetics for the glucose carriers at the BBB (Gruetter et al. 1996). These experiments were recently repeated by Shestov et al. (2011), who determined both $T_{\max }$ and $\mathrm{CMR}_{\mathrm{glc}}$ rates using the reversible $\mathrm{MM}$ model applied to brain glucose concentrations measured by dynamic ${ }^{1} \mathrm{H}$ NMR spectroscopy. These authors, however, failed to determine $K_{\mathrm{t}}$, which was then estimated from previously reported steadystate experiments (Gruetter et al. 1998; de Graaf et al. 2001).

Therefore, we tested the hypothesis that simultaneous dynamic measurement of brain and plasma glucose concentrations in vivo allows to determine independent rates for both glucose transport and consumption, that is, $T_{\max }$ and $\mathrm{CMR}_{\text {glc }}$, as well as $K_{\mathrm{t}}$ and $K_{\mathrm{ii}}$, using the four-state conformational model of the glucose carrier.

\section{Materials and methods}

\section{Animals}

All experimental procedures involving animals were approved by the local ethics committee. The experiments were performed with special care to minimise animal pain or discomfort. Male SpragueDawley rats $(259.0 \pm 5.8 \mathrm{~g}, n=14$, obtained from Charles River Laboratoires, France) were prepared as previously described (Duarte et al. 2009a, 2011a). Briefly, rats were anaesthetized using 2\% (v/v) isoflurane (Attane, Minrad, NY, USA) in 30\% (v/v) oxygen in air, and then intubated with an endotracheal catheter and ventilated with a pressure-driven ventilator (MRI-1; CWE Inc., Ardmore, PA, USA). Polyethylene catheters were inserted into a femoral artery for monitoring blood gases, arterial blood pressure, and glucose and lactate concentrations, and into a femoral vein for infusion of saline solutions containing $\alpha$-chloralose (Acros Organics, Geel, Belgium) or D-glucose (Sigma-Aldrich, Basel, Switzerland).

Animals were immobilised in a home-built holder with a bite bar and two ear inserts to minimize potential motion. Body temperature was maintained around $37.5^{\circ} \mathrm{C}$ with a warm water circulation system based on the feedback obtained from a homebuilt rectal temperature probe. Arterial blood pressure, heart rate and respiratory rate were continuously measured with an animal monitoring system (SA Instruments, Stony Brook, NY, USA).

Anaesthesia was switched to $\alpha$-chloralose consisting of an intravenous bolus of $80 \mathrm{mg} / \mathrm{kg}$ and continuous infusion rate of $28 \mathrm{mg} / \mathrm{kg} / \mathrm{h}$ (Duarte et al. 2009a, 2011a). Before NMR measurements, animals were allowed to stabilize for at least $40 \mathrm{~min}$ to avoid remaining effects of isoflurane. D-Glucose $[20 \%(\mathrm{w} / \mathrm{v})$ in saline solution] was given as a bolus and then continuously infused at a rate adjusted based on concomitantly measured arterial plasma glucose concentrations to maintain a stable plasma glucose concentration. Arterial $\mathrm{pH}$ and pressures of $\mathrm{O}_{2}$ and $\mathrm{CO}_{2}$ were measured using a blood gas analyser (AVL Compact 3; Diamond Diagnostics, Holliston, MA, USA). Plasma glucose and lactate concentrations were quantified by the glucose oxidase and lactate oxidase methods, respectively, using two multi-assay analysers (GW7 Micro-Stat; Analox Instruments, London, UK).

To modulate glucose transport and consumption, these experiments were then repeated either under isoflurane or deep thiopental anaesthesia instead of $\alpha$-chloralose. Sodium thiopental (Ospedalia AG, Hunenberg, Switzerland) was given as an intra-venous bolus of $50 \mathrm{mg} / \mathrm{kg}$ which was followed by $80 \mathrm{mg} / \mathrm{kg} / \mathrm{h}$ continuous rate infusion. This thiopental dose was found to induce iso-electricity after $90 \mathrm{~min}$ of infusion, as determined by electroencephalography in a previous study (Lei et al. 2010). Therefore, NMR measurements were only initiated after 90 min under thiopental anaesthesia. For experiments under isoflurane anaesthesia, rats were allowed to spontaneously breathe $1.5 \%(\mathrm{v} / \mathrm{v})$ isoflurane [in mixture of $30 \%(\mathrm{v} /$ v) oxygen in air]. Physiological parameters were similar between the three experimental groups, with exception of plasma lactate concentration (Table 1).

\section{NMR spectroscopy}

All experiments were performed in a Direct Drive spectrometer (Agilent, Palo Alto, CA, USA) interfaced to an actively shielded 9.4 $\mathrm{T}$ magnet with a $31 \mathrm{~cm}$ horizontal bore (Magnex Scientific, Abingdon, UK) using a homebuilt $12 \mathrm{~mm}{ }^{1} \mathrm{H}$ quadrature surface coil. The rat brain was positioned in the isocentre of the magnet and fast-spin-echo images with repetition time of $5 \mathrm{~s}$, echo time of $52 \mathrm{~ms}$ and echo train length of 8 allowed to identify anatomical landmarks, which were used to place the volume of interest (VOI) in the cortex and hippocampus. Shimming was performed with FAST(EST)MAP (Gruetter and Tkác 2000), and ${ }^{1} \mathrm{H}$ NMR spectra were acquired from a VOI size of $120 \mu \mathrm{L}$ using SPECIAL (Mlynárik et al. 2006) with echo time of $2.8 \mathrm{~ms}$ and repetition time of $4 \mathrm{~s}$. Spectra were saved in blocks of eight scans, corrected for the $B_{0}$ drift and summed at a convenient time resolution.

Spectral analysis was carried out using LCModel (Stephen Provencher Inc., Oakville, Ontario, Canada) including a macromolecule spectrum in the database (Mlynárik et al. 2006). The unsuppressed water signal measured from the same VOI was used as internal reference for absolute quantification of 20 metabolites: 
Table 1 Physiological variables shown as mean \pm SEM of 7, 5 and 5 rats for $\alpha$-chloralose, thiopental and isoflurane anaesthesia, respectively. Only lactate concentration was significantly increased under isoflurane anaesthesia compared with both $\alpha$-chloralose and thiopental $(p<0.01)$ using the one-way ANOVA followed by the Newman-Keuls multiple comparison test

\begin{tabular}{|c|c|c|c|}
\hline & $\alpha$-Chloralose & Thiopental & Isoflurane \\
\hline Temperature $\left({ }^{\circ} \mathrm{C}\right)$ & $37.2 \pm 0.2$ & $37.4 \pm 0.2$ & $37.7 \pm 0.2$ \\
\hline Heart rate $\left(\mathrm{min}^{-1}\right)$ & $388 \pm 58$ & $335 \pm 23$ & $382 \pm 29$ \\
\hline Mean arterial pressure $(\mathrm{mm} \mathrm{Hg})$ & $142 \pm 13$ & $120 \pm 18$ & $132 \pm 19$ \\
\hline Plasma lactate (mM) & $2.8 \pm 0.2$ & $3.9 \pm 0.5$ & $7.0 \pm 1.1$ \\
\hline Arterial Ph & $7.37 \pm 0.02$ & $7.38 \pm 0.03$ & $7.37 \pm 0.02$ \\
\hline $\mathrm{P}_{\mathrm{a}} \mathrm{CO}_{2}(\mathrm{mmHg})$ & $39.3 \pm 0.8$ & $40.6 \pm 2.8$ & $41.4 \pm 1.1$ \\
\hline $\mathrm{P}_{\mathrm{a}} \mathrm{O}_{2}(\mathrm{mmHg})$ & $188.2 \pm 6.5$ & $179.5 \pm 12.9$ & $180.4 \pm 14.9$ \\
\hline Arterial $\mathrm{O}_{2}$ saturation (\%) & $99.6 \pm 0.1$ & $99.5 \pm 0.1$ & $99.5 \pm 0.1$ \\
\hline
\end{tabular}

glucose, $\gamma$-aminobutyrate, alanine, $\mathrm{N}$-acetylaspartate, $\mathrm{N}$-acetylaspartylglutamate, ascorbate, aspartate, creatine, glutamate, glutamine, glutathione, glycerophosphorylcholine, $\beta$-hydroxybutyrate, myoinositol, scyllo-inositol, lactate, phosphocreatine, phosphorylcholine, phosphorylethanolamine, taurine (see details in Duarte et al. 2011c). As the inclusion of glucose $\mathrm{H} 1 \alpha$ resonance at $5.23 \mathrm{ppm}$ does not significantly contribute for the reliability in the estimation of glucose concentration (analysed by Shestov et al. 2011), LCModel analysis was performed using the spectral range between 0.5 and $4.5 \mathrm{ppm}$, thus avoiding spectral manipulation for residual water peak removal. The Cramér-Rao lower bound (CRLB) provided by LCModel for each metabolite was used as measure of the reliability of the quantified metabolite concentration.

\section{Kinetic model of glucose transport}

The BBB was assumed to behave as a single membrane separating the blood circulation compartment from the brain aqueous phase. This is in agreement with a relatively small distribution space for glucose inside endothelial cells, a fast rate of transport compared with endothelial glucose consumption and glucose carriers largely more concentrated in the membrane of brain cells than in luminal or abluminal membranes of the endothelium (discussed in Gjedde and Christensen 1984; Barros et al. 2007; Simpson et al. 2007). Therefore, diffusion across cell membranes of astrocytes and neurons is not limiting for the global rate of glucose transport, consistent with similar intra- and extracellular glucose concentrations (e.g. Pfeuffer et al. 2000).

Transport across the BBB was described using unidirectional fluxes and symmetric kinetic constants for influx and efflux, as in previous studies (e.g. Cunningham et al. 1986; Mason et al. 1992; Gruetter et al. 1998; Duarte et al. 2009b). Briefly, glucose selectively binds to facilitative glucose carriers that mediate solute movement in both directions of the BBB along a concentration gradient, which is maintained by continuous phosphorylation of intracellular glucose (e.g. Gruetter et al. 1998; Barros et al. 2007; Duarte et al. 2009b). Considering that the BBB is defined as a single membrane (discussed in Duarte et al. 2009b), brain glucose concentration $\left(G_{\text {brain }}\right)$ over time is defined by

$$
\frac{\mathrm{dG}_{\mathrm{brain}}(\mathrm{t})}{\mathrm{dt}}=\mathrm{T}^{\mathrm{f}}-\mathrm{T}^{\mathrm{r}}-\mathrm{CMR}_{\mathrm{glc}}
$$

where $G_{\text {brain }}$ is given in $\mu \mathrm{mol} / \mathrm{g}$ and the rates of glucose influx $\left(T^{f}\right)$ or efflux $\left(T^{r}\right)$ across the BBB, as well as $\mathrm{CMR}_{\mathrm{glc}}$, are in $\mu \mathrm{mol} / \mathrm{g} / \mathrm{min}$.
Figure 1 represents the alternating-conformation model for a membrane carrier in which the carrier protein may occur in four distinct conformations: when unloaded, it can exist in two interconverting isomers that are ready to bind glucose either outside or inside the membrane; when bound to glucose, it can assume two conformations favouring glucose release to the outer or inner sides of the membrane (e.g. Cuppoletti and Segel 1975). The use of the

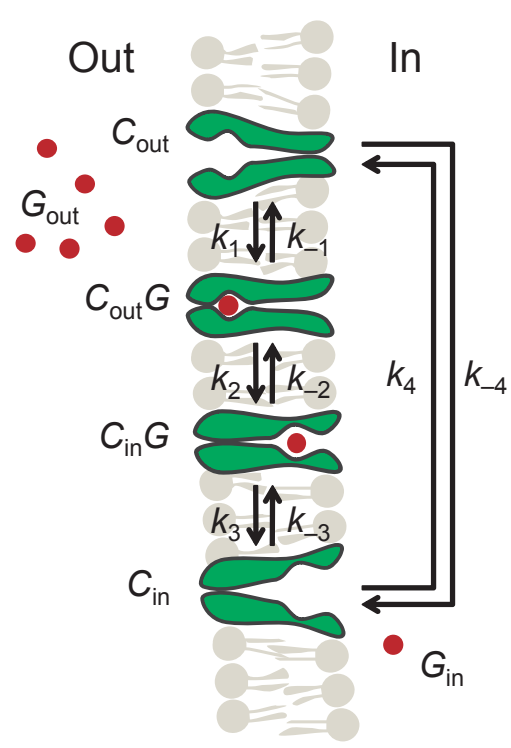

Fig. 1 The alternating-conformation model. The glucose carrier exists in four conformations: when loaded, it can isomerise between conformations that favour glucose release to either the outer $\left(C_{\text {out }} G\right)$ or the inner $\left(C_{\text {in }} G\right)$ side of the membrane; in the free form, it exists in two inter-converting isomers $\mathrm{C}_{\text {out }}$ or $\mathrm{C}_{\text {in }}$ that are ready to bind glucose in either of the membrane sides. The rate constants $k_{1}$ and $k_{-3}$ define glucose binding while $k_{-1}$ and $k_{3}$ define its dissociation from the carrier. The rate constants $k_{2}$ and $k_{-2}$ or $k_{4}$ and $k_{-4}$ reflect the isomerisation of the loaded or unloaded carrier, respectively. A fast isomerisation of the unloaded carrier, that is, for $k_{4}$ and $k_{-4}$ much larger than the other rate constants, is equivalent to a simple reversible MM kinetics (Duarte et al. 2009b). Figure was adapted from Duarte et al. (2009b), where the relation between rate constants and the kinetic parameters was explained in detail. 
four-state conformational model of solute carriers to describe glucose transport across the BBB was previously detailed elsewhere (Duarte et al. 2009b). Despite the asymmetry of individual glucose carriers (reviewed in Simpson et al. 2007), the global glucose transport mechanism across the BBB has been found to approach symmetry (e.g. Barros et al. 2007; Duarte et al. 2009b), which was thus assumed in the present model (see discussion). Using this fourstate conformational kinetics, $G_{\text {brain }}$ as function of $G_{\text {plasma }}$ and time $(t)$ is then given by

$$
\frac{\mathrm{dG}_{\text {brain }}(\mathrm{t})}{\mathrm{dt}}=\frac{\mathrm{T}_{\max }\left(\mathrm{G}_{\text {plasma }}(\mathrm{t})-\frac{\mathrm{G}_{\text {brain }}(\mathrm{t})}{\mathrm{V}_{\mathrm{d}}}\right)}{\mathrm{K}_{\mathrm{t}}+\frac{\mathrm{G}_{\text {brain }}(\mathrm{t})}{\mathrm{V}_{\mathrm{d}}}+\mathrm{G}_{\text {plasma }}(\mathrm{t})\left(1+\frac{\mathrm{G}_{\text {brain }}(\mathrm{t})}{\mathrm{V}_{\mathrm{d}} \mathrm{K}_{\mathrm{ii}}}\right)}-\mathrm{CMR}_{\mathrm{glc}}
$$

where $G_{\text {brain }}$ and $G_{\text {plasma }}$ are the concentrations of glucose in brain (in $\mu \mathrm{mol} / \mathrm{g}$ ) and in plasma (in $\mathrm{mM}$ ), $T_{\max }$ denotes the apparent maximal transport rate across the BBB $(\mu \mathrm{mol} / \mathrm{g} / \mathrm{min}), K_{\mathrm{t}}$ and $K_{\mathrm{ii}}$ denote the apparent Michaelis and iso-inhibition constants (in $\mathrm{mM}$ ), $V_{\mathrm{d}}$ is the volume of the physical distribution space of glucose in the brain $(0.77 \mathrm{~mL} / \mathrm{g})$ (Lund-Andersen 1979$)$.

From eqn 2 it is apparent that if $K_{\text {ii }}$ largely exceeds $G_{\text {brain }}$, the model approximates the kinetics of a reversible MM model, which is equivalent to the four-state conformational model with fast exchange rates between unloaded carrier conformations (Duarte et al. 2009b).

\section{Determination of kinetic parameters}

The contribution of $G_{\text {plasma }}$ to the measured $G_{\text {brain }}$ was subtracted assuming a blood volume in the brain of $35 \mu \mathrm{L} / \mathrm{g}$ (Shockley and LaManna 1988). The kinetic parameters were estimated for both four-state conformational model and reversible model of glucose transport (assuming $K_{\mathrm{ii}} \gg>\mathrm{G}_{\text {brain }}$, i.e. $G_{\text {brain }} / K_{\mathrm{ii}}=0$ ). $\mathrm{CMR}_{\text {glc }}$ was considered to be constant in the range of glucose concentrations analysed. However, as brain glucose levels varied through the experimental protocol, for the sake of comparison, glucose consumption was also analysed with an irreversible MM kinetics for glucose phosphorylation by hexokinase (ATP:D-hexose 6phosphotransferase, EC 2.7.1.1). In this case, hexokinase was considered to have irreversible MM kinetics and fits to the data were performed with free $V_{\max }{ }^{\mathrm{HK}}$ but $K_{\mathrm{M}}{ }^{\mathrm{HK}}$ constrained to $50 \mu \mathrm{M}$ (WeilMalherbe and Bone 1951; Grossbard and Schimke 1966; Schimke and Grossbard 1968; Buschiazzo et al. 1970; Gjedde 1982; Sprengers et al. 1983). If not constrained, $K_{\mathrm{M}}{ }^{\mathrm{HK}}$ was poorly estimated with any of the tested models.

Each model was fitted to $G_{\text {brain }}$ as function of $G_{\text {plasma }}$ over the entire measured time courses using the Levenberg-Marquardt algorithm for non-linear regression, coupled to a Runge-Kutta method for non-stiff systems to obtain numerical solutions of the ordinary differential equations. Fit quality was assessed by MonteCarlo analysis, in which gaussian noise with the same variance of fit residuals was added to the best fit and initial conditions were randomly generated within confidence interval of the obtained value. Typically, 1000 simulated datasets were created for each individual analysis. These Monte-Carlo simulations allowed estimating the standard deviation for each parameter in a single experiment. Significance of the fitted kinetic parameters was inferred from t-statistics. The $F$-statistics was used to compare the different models that have been fit to each data set. All numerical procedures were performed in Matlab (The MathWorks, Natick,
MA, USA). Data are shown as mean \pm SEM of $n$ experiments unless otherwise indicated. Effect of anaesthesia on kinetic parameters was determined by ANOVA followed by NewmanKeuls multiple comparison tests and considered significant when $p<0.05$.

\section{Results}

Reliable quantification of glucose was achieved with a time resolution of $3 \mathrm{~min}$ from ${ }^{1} \mathrm{H} \mathrm{NMR}$ spectra acquired in vivo from a volume of $120 \mu \mathrm{L}$ located in cortical and hippocampal areas (Fig. 2). However, to ensure enough signal to noise ratio for glucose quantification at euglycaemia, time resolution of 5 min was preferred as it resulted in CRLB of glucose consistently bellow $15 \%$. In particular, from all analysed data-sets, CRLB for glucose were $11-13 \%$ at euglycaemia and decreased to $3 \%$ upon glucose infusion. $G_{\text {brain }}$ increased at a rate reflecting both glucose transport across the $\mathrm{BBB}$ and continuous glucose consumption

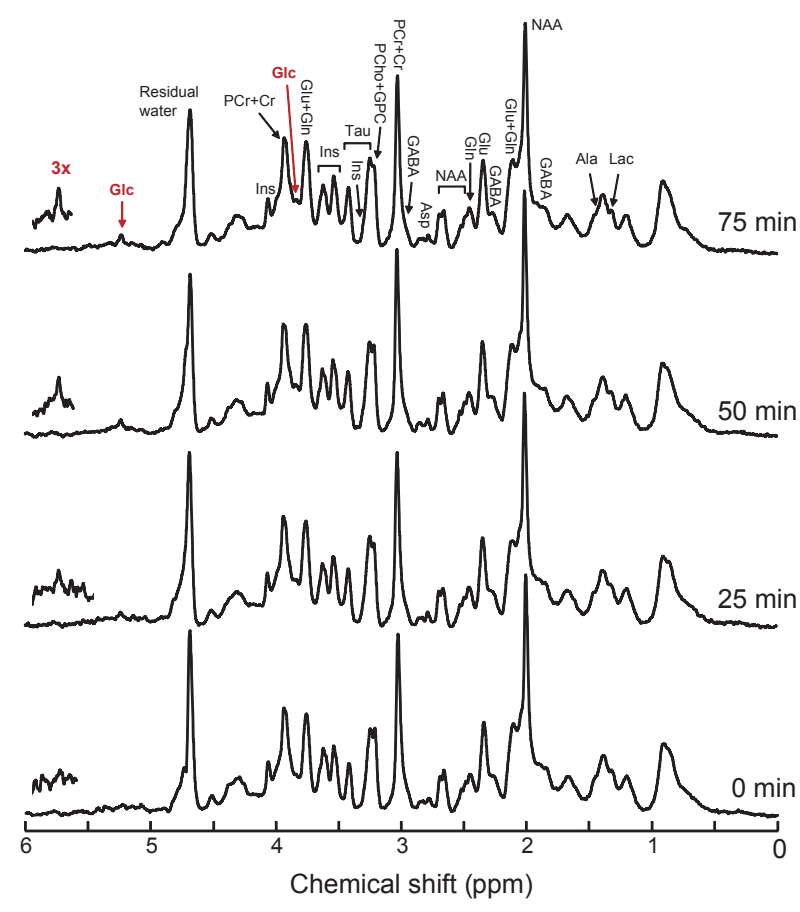

Fig. 2 Typical ${ }^{1} \mathrm{H}$ NMR spectra at 9.4 $\mathrm{T}$ acquired in vivo during the time course of glucose infusion. These example spectra were acquired during $3 \mathrm{~min}$ after $0,25,50$ and $75 \mathrm{~min}$ of 'step-function' glucose infusion. Several metabolites are identified in the spectrum, including discernible resonances of glucose (red label). The expansion on the right of each spectrum is the respective peak of glucose at $5.22 \mathrm{ppm}$. Metabolites in the spectra are assigned as follows: glucose (Glc), creatine (Cr), phosphocreatine (PCr), myo-inositol (Ins), taurine (Tau), $\mathrm{N}$-acetylaspartate (NAA), aspartate (Asp), glutamate (Glu), glutamine (GIn), $\gamma$-aminobutyrate (GABA), alanine (Ala), lactate (Lac), glycerophosphorylcholine (GPC) phosphorylcholine (PCho), N-acetylaspartylglutamate (NAAG). 


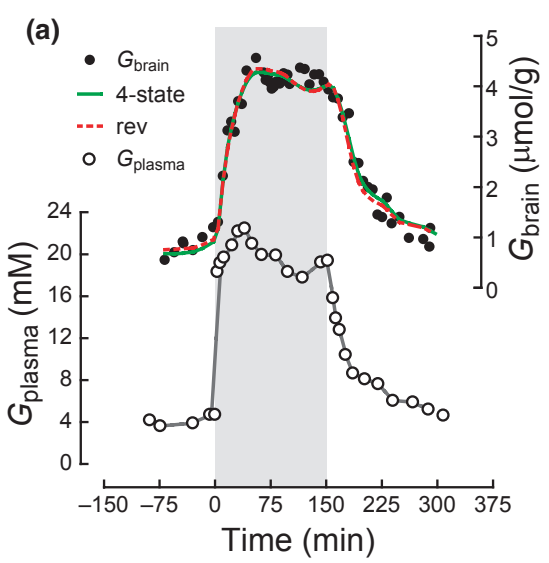

(c)

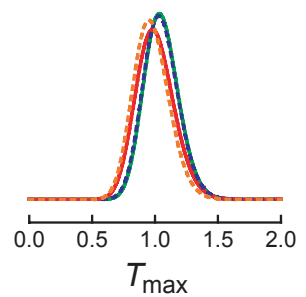

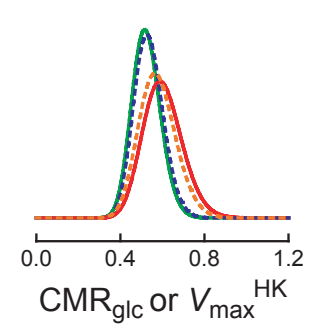

(d)

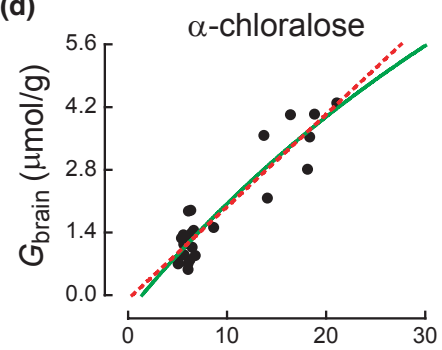

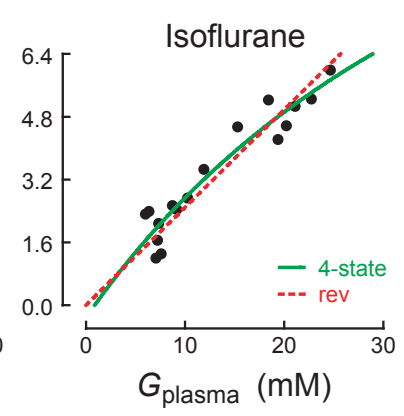

(b)
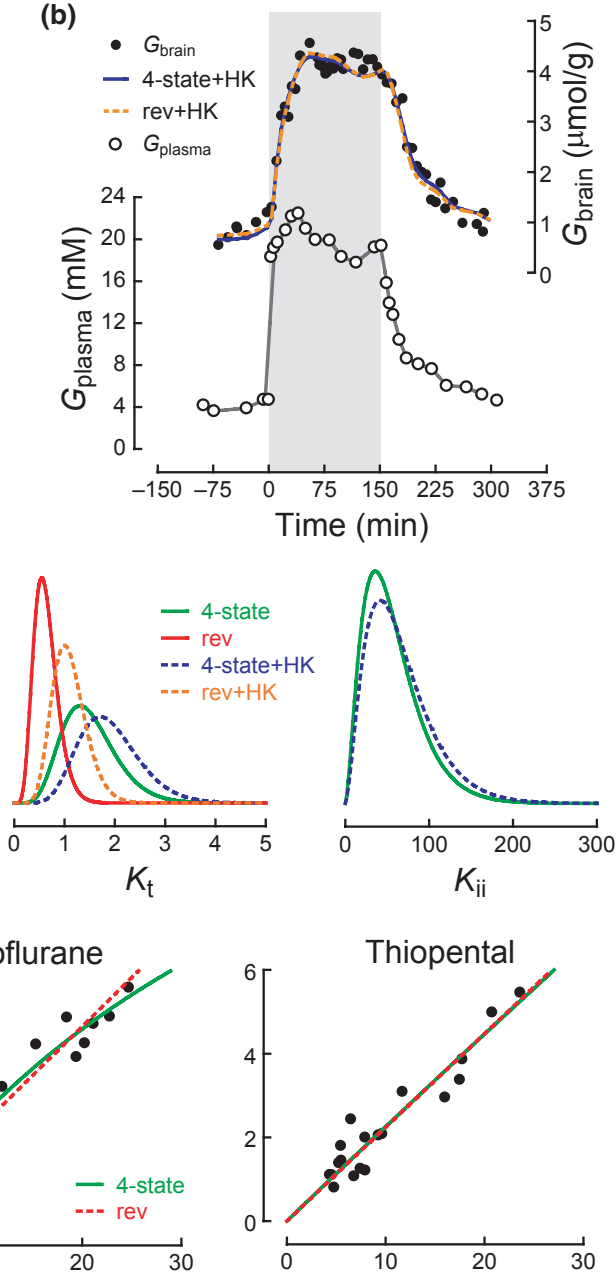

Fig. 3 Panels (a) and (b) show the best fit of the conformational (green/blue) and reversible (red/orange) models to $G_{\text {brain }}$ with BBB as a single membrane in a representative data set (one rat), under $\alpha$-chloralose anaesthesia. Panel (a) shows the fit when constant glucose consumption is assumed. In panel (b), hexokinase was modelled with a standard MM kinetics. $G_{\text {plasma }}$ was interpolated for the time scale of $G_{\text {brain }}$ (gray line). In general, $F$-statistics indicated good fit (large $f$-values) and all determined parameters were significant, as evaluated with a t-statistics. In this particular case, $t\left(T_{\max }\right)=36.2$, $t\left(K_{\mathrm{t}}\right)=9.40, \quad t\left(\mathrm{CMR}_{\mathrm{glc}}\right)=35.4$ with $R^{2}=0.966$ and $f=557$ for the reversible MM model; $t\left(T_{\max }\right)=36.7, \quad t\left(K_{\mathrm{t}}\right)=12.2, \quad t\left(K_{\mathrm{ii}}\right)=12.8$, $t\left(\mathrm{CMR}_{\mathrm{glc}}\right)=40.0$ with $R^{2}=0.969$ and $f=450$ for the conformational model. When assuming that hexokinase behaves as a MM enzyme (with $\mathrm{K}_{\mathrm{M}}{ }^{\mathrm{HK}}=50 \mu \mathrm{M}$ ) instead of considering constant $\mathrm{CMR}_{\mathrm{glc}}$, for this particular experiment, $t\left(T_{\max }\right)=47.9, t\left(K_{\mathrm{t}}\right)=8.76, t\left(V_{\max }^{\mathrm{HK}}\right)=45.9$ with $R^{2}=0.966$ and $f=555$ for the reversible MM model; $t\left(T_{\max }\right)=29.2$, $t\left(K_{\mathrm{t}}\right)=8.04, t\left(K_{\mathrm{ii}}\right)=6.70, t\left(V_{\max }{ }^{\mathrm{HK}}\right)=45.2$ with $R^{2}=0.969$ and $f=453$ for the conformational model. Therefore, one can infer that, although fit

(Fig. 3a and b). Similarly, when glucose in the plasma dropped to normoglycaemia, that is, upon cessation of glucose infusion, $G_{\text {brain }}$ decayed accordingly. The dynamics adequacy is good with any of the models, metabolic rates are more significant than apparent affinity and iso-inhibition constants. Panel (c) shows probability density functions determined from Monte-Carlo simulations. The graphs include the density function for the conformational and reversible model assuming a single membrane at the BBB. While rate constants approximated a Gaussian distribution, the distribution for affinity and iso-inhibition constants was rather described with gamma functions that approximated an exponential for the reversible model. Panel (d) depicts a steady-state analysis of the present data from rats under $\alpha$-chloralose $(n=7)$, isoflurane $(n=5)$ and deep thiopental $(n=5)$ anaesthesia. As all the experiments here performed had generally three stead-state periods, consisting of baseline, hyperglycaemia and baseline after glycaemia decay, steadystate $G_{\text {brain }}$ measurements in function of $G_{\text {plasma }}$ were used for steadystate analysis as previously described (Duarte et al. 2009b). Best fit of the reversible and four-state conformational models is depicted by the red and green lines, respectively. Results from steady-state analysis are shown in Table 3.

of $G_{\text {brain }}$ measured by ${ }^{1} \mathrm{H}$ NMR spectroscopy in vivo was thus used to determine rates of consumption and transport, as well as affinity and inhibition constants. The concentra- 
Table 2 Kinetic parameters of glucose transport and consumption in the rat brain as determined in vivo by dynamic ${ }^{1} \mathrm{H}$ NMR spectroscopy under light $\alpha$-chloralose anaesthesia. $T_{\text {max }}, \mathrm{CMR}_{\text {glc }}$ and $V_{\max }{ }^{\mathrm{HK}}$ are given in $\mu \mathrm{mol} / \mathrm{g} / \mathrm{min}$ while $K_{\mathrm{t}}$ and $K_{\mathrm{ii}}$ and $K_{\mathrm{M}}{ }^{\mathrm{HK}}$ are in $\mathrm{mM}$. Data are mean $\pm \mathrm{SEM}$ of seven experiments

\begin{tabular}{|c|c|c|c|c|}
\hline \multirow{3}{*}{$\begin{array}{l}\text { Four-state } \\
\text { conformational model }\end{array}$} & \multicolumn{2}{|c|}{ Constant $\mathrm{CMR}_{\mathrm{glc}}$} & \multicolumn{2}{|c|}{$\begin{array}{l}\text { With MM kinetics for } \\
\text { hexokinase* }^{*}\end{array}$} \\
\hline & $T_{\max }$ & $1.03 \pm 0.18$ & $T_{\max }$ & $1.02 \pm 0.16$ \\
\hline & $K_{\mathrm{t}}$ & $1.43 \pm 0.33$ & $K_{\mathrm{t}}$ & $1.80 \pm 0.54$ \\
\hline & $K_{\mathrm{ii}}$ & $50.3 \pm 16.0$ & $K_{\mathrm{ii}}$ & $58.6 \pm 20.9$ \\
\hline & $\mathrm{CMR}_{\mathrm{glc}}$ & $0.52 \pm 0.09$ & $V_{\max }{ }^{\mathrm{HK}}$ & $0.53 \pm 0.09$ \\
\hline & $T_{\text {max }} / \mathrm{CMR}_{\mathrm{glc}}$ & $2.03 \pm 0.21$ & $T_{\max } / \mathrm{CMR}_{\mathrm{glc}}{ }^{* *}$ & $2.09 \pm 0.18$ \\
\hline \multirow[t]{4}{*}{ Reversible model } & $T_{\max }$ & $0.99 \pm 0.18$ & $T_{\max }$ & $0.96 \pm 0.18$ \\
\hline & $K_{\mathrm{t}}$ & $0.64 \pm 0.27$ & $K_{\mathrm{t}}$ & $1.09 \pm 0.48$ \\
\hline & $\mathrm{CMR}_{\mathrm{glc}}$ & $0.59 \pm 0.11$ & $V_{\max }{ }^{\mathrm{HK}}$ & $0.57 \pm 0.11$ \\
\hline & $T_{\text {max }} / \mathrm{CMR}_{\mathrm{glc}}$ & $1.68 \pm 0.08$ & $T_{\text {max }} / \mathrm{CMR}_{\mathrm{glc}}{ }^{\star *}$ & $1.77 \pm 0.08$ \\
\hline
\end{tabular}

${ }^{*} \mathrm{~K}_{\mathrm{M}}{ }^{\mathrm{HK}}$ was fixed at $50 \mu \mathrm{M} ;{ }^{* *} \mathrm{~T}_{\mathrm{max}} / \mathrm{CMR}_{\mathrm{glc}}$ calculated for $\mathrm{G}_{\mathrm{brain}}=1 \mu \mathrm{mol} / \mathrm{g}$.

Table 3 Kinetic parameters of glucose transport and consumption in the brain as determined in vivo by ${ }^{1} \mathrm{H}$ NMR spectroscopy at steady-state under $\alpha$-chloralose $(n=7)$, isoflurane $(n=5)$ and thiopental $(n=5)$ anaesthesia. BBB was considered to behave as a single membrane. $T_{\text {max }}$ $\mathrm{CMR}_{\mathrm{glc}}$ is dimensionless and both $K_{\mathrm{t}}$ and $K_{\mathrm{ii}}$ are in $\mathrm{mM}$. Results of the best fit are shown with confidence intervals

\begin{tabular}{|c|c|c|c|c|}
\hline & & $\alpha$-Chloralose & Isoflurane & Thiopental \\
\hline \multirow[t]{4}{*}{ Four-state conformational model } & $T_{\text {max }} / \mathrm{CMR}_{\mathrm{glc}}$ & $2.06(0 ; 4.57)$ & $2.75(0 ; 7.62)$ & $1.84(0.70 ; 2.98)$ \\
\hline & $K_{\mathrm{t}}$ & $1.49(0 ; 10.45)$ & $1.54(0 ; 17.67)$ & 0 \\
\hline & $K_{\mathrm{ii}}$ & $26.4(0 ; 227.1)$ & $13.4(0 ; 82.6)$ & $347.0(0 ; 6041.0)$ \\
\hline & & $\left(R^{2}=0.859\right)$ & $\left(R^{2}=0.860\right)$ & $\left(R^{2}=0.899\right)$ \\
\hline \multirow[t]{3}{*}{ Reversible model } & $T_{\text {max }} / \mathrm{CMR}_{\mathrm{glc}}$ & $1.73(1.56 ; 1.91)$ & $1.96(1.71 ; 2.20)$ & 1.82 (1.70; 1.94) \\
\hline & $K_{\mathrm{t}}$ & $0.32(0 ; 1.70)$ & 0 & $0.10(0 ; 1.10)$ \\
\hline & & $\left(R^{2}=0.907\right)$ & $\left(R^{2}=0.887\right)$ & $\left(R^{2}=0.899\right)$ \\
\hline
\end{tabular}

tions of other measured metabolites were not significantly altered upon glucose infusion.

The data resolution obtained from a single experiment led to significant fits for all of the models of glucose transport, as determined by $f$-statistics (Fig. 3a and b). Kinetic parameters are shown in Table 2 for the rat brain under $\alpha$-chloralose anaesthesia. Both $T_{\max }$ and $\mathrm{CMR}_{\mathrm{glc}}$ (or $V_{\max }{ }^{\mathrm{HK}}$ ) were consistently estimated with small calculated errors for both the reversible and four-state conformational models (Table 2), as depicted from high $t$ values and a Gaussian probability density function (see example in Fig. 3). That was not the case for the apparent affinity and iso-inhibition constants that, in most cases, displayed a nearly exponential probability density function, suggesting that the glucose transport models were less efficient in constraining $K_{\mathrm{t}}$ and $K_{\mathrm{ii}}$. In fact, $t$-statistics indicated that $K_{\mathrm{t}}$ was not significantly different from zero when using the reversible MM model (Fig. 3c). The concentration of glucose at half-maximal transport $K_{\mathrm{t}}$ was however better estimated with the four-state conformational than with the reversible model (Fig. 3). Under $\alpha$-chloralose anaesthesia, $K_{\mathrm{t}}$ was $1.43 \pm 0.33 \mathrm{mM}$. The iso-inibition constant $K_{\mathrm{ii}}$ was $50.3 \pm 16.0 \mathrm{mM}$, which was not significantly different from when hexokinase activity was modelled as an irreversible MM enzyme. As it was much larger than brain glucose concentrations observed in this study, $K_{\mathrm{ii}}$ was less well estimated than the other parameters, and was associated with larger relative standard deviation.

In addition to the transient changes in brain glucose content, steady-state $G_{\text {brain }}$ was available at hyper- and euglycaemia. Therefore, a steady-state analysis of glucose transport was performed as previously described (Duarte et al. 2009b). Fitted $G_{\text {brain }}$ as function of $G_{\text {plasma }}$ (Fig. 3d) resulted in $T_{\text {max }} / \mathrm{CMR}_{\mathrm{glc}}$ similar to those determined with the current dynamic strategy (Table 3).

With the estimated kinetic parameters (Table 2), we simulated $G_{\text {brain }}$ as function of $G_{\text {plasma }}$ at either non-steadystate or steady-state (Fig. 4). From these simulations, we determined normal $G_{\text {brain }}$ at euglycaemia (i.e. $G_{\text {plasma }}$ of $5.5 \mathrm{mM}$ ), to be $0.9 \mu \mathrm{mol} / \mathrm{g}$ with any of the models employed, consistent with numerous NMR or microdialysis measurements in vivo (reviewed in Barros et al. 2007). To this $G_{\text {brain }}$ concentration adds the contribution of $G_{\text {plasma }}$ in a blood volume of $35 \mu \mathrm{L} / \mathrm{g}$ of brain tissue, and thus the $G_{\text {brain }}$ measured by ${ }^{1} \mathrm{H}$ NMR spectroscopy is $1.1 \mu \mathrm{mol} / \mathrm{g}$, in agreement with $1.2 \pm 0.2 \mu \mathrm{mol} / \mathrm{g}$ measured under $\alpha$-chloralose at $5.5 \pm 0.2 \mathrm{mM}$ of $G_{\text {plasma }}(n=7)$. From the performed simulations, we also verified that $\mathrm{CMR}_{\mathrm{glc}}$ was unaltered at euglycaemia and above (Fig. 4c). 

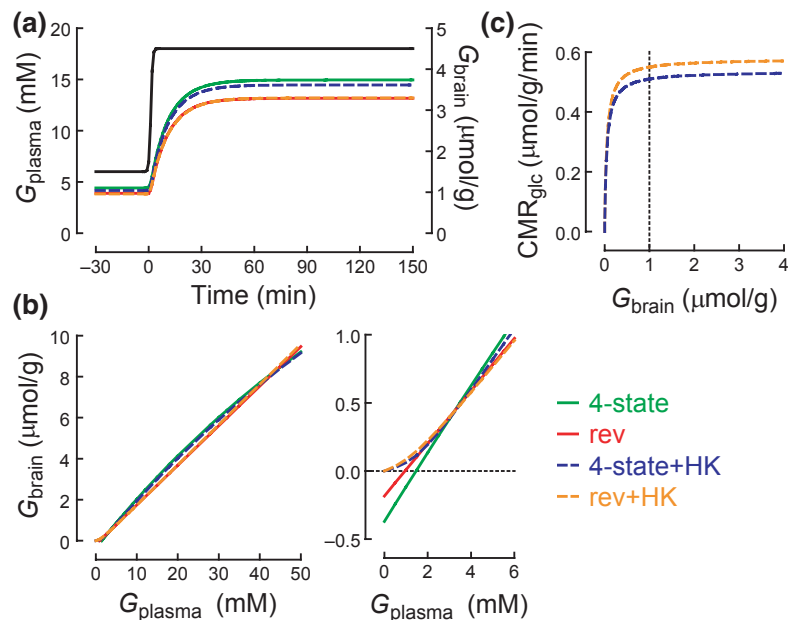

$$
\begin{aligned}
& \text { - 4-state } \\
& \text { - rev } \\
& \text {-- 4-state+HK } \\
& \text {-- rev+HK }
\end{aligned}
$$

Fig. 4 The estimated kinetic parameters (Table 2) were used to simulate $G_{\text {brain }}$ for a given $G_{\text {plasma }}$ function at non-steady-state (a) and steady-state (b). Black line represents plasma glucose function. Simulations were performed with the conformational and reversible models assuming either constant $\mathrm{CMR}_{\mathrm{glc}}$ (solid lines) or MM kinetics for hexokinase with $K_{\mathrm{M}}{ }^{\mathrm{HK}}$ fixed at $50 \mu \mathrm{M}$ (dashed lines). In (b), the graph on the right is an expansion for plasma glucose bellow $6 \mathrm{mM}$. Panel (c) shows the resulting $\mathrm{CMR}_{\mathrm{glc}}$ as function of $G_{\text {brain, validating the }}$ assumption of invariable $\mathrm{CMR}_{\mathrm{glc}}$ above $1 \mu \mathrm{mol} / \mathrm{g}$ of $G_{\text {brain }}$.

As cerebral glucose metabolism is dependent on neuronal activity, we tested the effect of deep thiopental anaesthesia in the estimated kinetic metabolic parameters. Sodium thiopental was administered at a dose able to induce iso-electricity in the rat brain. In comparison to $\alpha$-chloralose anaesthetized rats, $T_{\max }$ and $\mathrm{CMR}_{\mathrm{glc}}$ were reduced by $42 \pm 10 \%(n=5$, $p<0.05)$ and $49 \pm 4 \%(n=5, p<0.05)$, respectively, while $K_{\mathrm{t}}$ and $K_{\mathrm{ii}}$ were not significantly different under both anaesthesia conditions (Fig. 5a). $T_{\max }$ and $K_{\text {ii }}$ tended to be respectively higher and lower under isoflurane anaesthesia than under $\alpha$-chloralose, although not significantly different. This was confirmed by higher glucose levels under isoflurane anaesthesia compared with $\alpha$-chloralose at steady-state (Fig. 3d). Figure 5b show simulations of $G_{\text {brain }}$ dynamics for a given $G_{\text {plasma }}$ using the kinetic parameters obtained for each anaesthesia protocol. In particular, deep thiopental anaesthesia caused a larger depression in $\mathrm{CMR}_{\mathrm{glc}}$ upon than in $T_{\max }$ and thus led to glucose accumulation in the brain.

\section{Discussion}

\section{Cerebral glucose transport and metabolism}

The metabolic rate of the brain is closely related to the glycolytic rate as glucose provides most cerebral energy supply (Siesjo 1978). There is abundant evidence that GLUT1 is the main glucose carrier at the BBB and that, under normal physiology, it is not limiting for the overall (a)
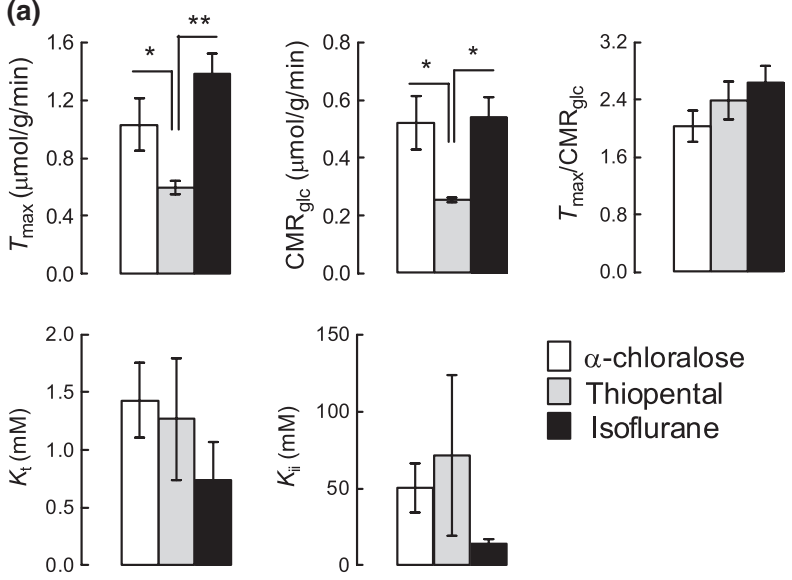

(b)

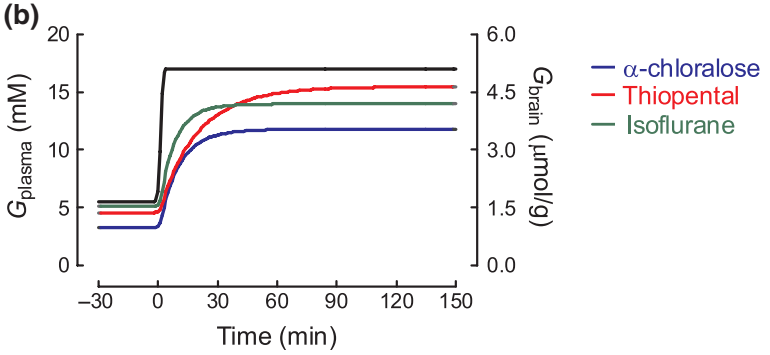

Fig. 5 Panel (a) shows the effect of isoflurane and deep thiopental anaesthesia on kinetic parameters of cerebral glucose transport and consumption, in comparison to light $\alpha$-chloralose anaesthesia. Glucose kinetics was evaluated with the four-state conformational model. $T_{\text {max }}$ and $\mathrm{CMR}_{\mathrm{glc}}$ are given in $\mu \mathrm{mol} / \mathrm{g} / \mathrm{min}$ while $K_{\mathrm{t}}$ and $K_{\mathrm{ii}}$ are in $\mathrm{mM}$. Data are mean \pm SEM of 7,5 and 5 rats for $\alpha$-chloralose, thiopental and isoflurane anaesthesia, respectively. Data comparison was performed with one-way ANOva followed by the Newman-Keuls multiple comparison test $\left({ }^{*} p<0.05,{ }^{\star *} p<0.01\right)$. Panel (b) depicts mathematical simulation of $G_{\text {brain }}$ levels as function of a given $G_{\text {plasma }}$ (black line) using the kinetic parameters determined for each of the anaesthesia types with the four-state conformational model.

brain glucose consumption rate (reviewed in Barros et al. 2007; Simpson et al. 2007). Glucose concentration in the brain is thus dependent on facilitated diffusion at the BBB and glucose phosphorylation by hexokinase. This study was designed to test the hypothesis that simultaneous measurement of glucose concentrations in plasma and brain upon modification of plasma glucose levels allow reliable estimation of kinetic parameters of cerebral glucose homeostasis, including the glucose metabolic rate.The present data shows that, by simultaneously measuring plasma and brain glucose concentrations, $T_{\max }$ and $\mathrm{CMR}_{\mathrm{glc}}$ can be independently determined in vivo and in a non-invasive way. In addition, using the four-state conformational model of glucose transport, we simultaneously determined $T_{\max }, K_{\mathrm{t}}, K_{\mathrm{ii}}$ and $\mathrm{CMR}_{\text {glc }}$. Under $\alpha$-chloralose anaesthesia, $\mathrm{CMR}_{\mathrm{glc}}$ of $0.52 \pm 0.09 \mu \mathrm{mol} / \mathrm{g} / \mathrm{min}$ was similar to determinations using $\left[1,6-{ }^{13} \mathrm{C}\right]$ glucose as tracer and detection by ${ }^{13} \mathrm{C}$ NMR spectroscopy in the whole brain (Duarte et al. 2011a) and 
to measures by autoradiography in the cortex and hippocampus (Ueki et al. 1992; Nakao et al. 2001), which are areas encompassed in the current VOI. Note that a small portion of the spectroscopy volume is constituted by white mater of the corpus callosum that has smaller $\mathrm{CMR}_{\mathrm{glc}}$ than gray matter (e.g. Sokoloff et al. 1977; Archer et al. 1990). In fact, through the different regions of the brain, $\mathrm{CMR}_{\mathrm{glc}}$ values ranging from 0.54 to $1.97 \mu \mathrm{mol} / \mathrm{g} / \mathrm{min}$ and from 0.33 to $0.40 \mu \mathrm{mol} / \mathrm{g} / \mathrm{min}$ were respectively reported for the gray matter and for white matter of the conscious rat (Sokoloff et al. 1977). The ratio of $T_{\max }$ to $\mathrm{CMR}_{\mathrm{glc}}$ determined in the present study is in agreement with previous findings in the rat brain under $\alpha$-chloralose anaesthesia (Duarte et al. 2009a,b, 2011a; Lei et al. 2010). The apparent affinity constant $K_{\mathrm{t}}$ was in the range of previous reports for steady-state experiments (Duarte et al. 2009b). $K_{\mathrm{ii}}$ was found to be much larger than $G_{\text {brain }}$ and in the same order of magnitude of that determined by steady-state models of glucose transport (Barros et al. 2007; Duarte et al. 2009b).

Like traditional steady-state models (e.g.Gruetter et al. 1998; Duarte et al. 2009a), the present dynamic model was designed with the assumption of symmetric glucose transport at the BBB. Transport asymmetry reflects different $K_{\mathrm{M}}$ and $V_{\max }$ for glucose uptake and release. However, the occurrence of nearly equal density of glucose asymmetric carriers on both sides of the BBB, that is, in luminal and abluminal membranes of the endothelium, presumably results in cancelation of the intrinsic asymmetry of individual carrier proteins (discussed in Barros et al. 2007; Simpson et al. 2007). Therefore, in previous studies, glucose diffusion at the BBB in vivo was found compatible with symmetric transport (Barros et al. 2007; Duarte et al. 2009b). Furthermore, a concentration gradient drives glucose transport from the plasma into the brain parenchyma and does not favour glucose release from the brain. The determined kinetic parameters are thus apparent constants that describe the global mechanism of net glucose transport.

Glucose accumulated in the brain upon glucose infusion, as consequence of the equilibrative nature of glucose transport across the BBB and a glycolytic flux operating close to its maximum rate, with $\mathrm{CMR}_{\text {glc }}$ unaltered at euglycaemia and above (Fig. 4c). In line with this, when glucose infusion ceased, the decay in cerebral glucose concentration was delayed and strongly dependent on glucose consumption that starts with its phosphorylation by hexokinase. We further determined kinetic parameters of the hexokinase activity, assuming irreversible MM kinetics. Without fixing any constraint to the fitting, for example with the conformational model of glucose transport, the apparent $K_{\mathrm{M}}$ of hexokinase was found to be $0.11 \pm 0.04 \mathrm{mM}$ for brain glucose (data not shown). However, as this parameter was poorly estimated and not significantly different from zero with any of the models, fits to the data were performed with $K_{\mathrm{M}}{ }^{\mathrm{HK}}$ constrained to
$50 \mu \mathrm{M}$, in accordance to the $K_{\mathrm{M}}$ of cytosolic hexokinase isolated from the rat brain ranging from 40 to $67 \mu \mathrm{M}$ (Grossbard and Schimke 1966; Schimke and Grossbard 1968; Sprengers et al. 1983). $K_{\mathrm{M}}{ }^{\mathrm{HK}}$ was also determined to be $50 \mu \mathrm{M}$ in rat brain extracts (Weil-Malherbe and Bone 1951), and to range between 30 to $40 \mu \mathrm{M}$ when indirectly calculated from experiments with radio-labelled glucose analogs (Buschiazzo et al. 1970; Gjedde 1982). With $K_{\mathrm{M}}{ }^{\mathrm{HK}}$ set to $50 \mu \mathrm{M}$ for glucose, under $\alpha$-chloralose anaesthesia, apparent $V_{\max }{ }_{\mathrm{HK}}$ was $0.53 \pm 0.09 \mu \mathrm{mol} / \mathrm{g} / \mathrm{min}$ when determined with the fourstate conformational model. This observation confirms that, in the conditions of the present study, brain hexokinase operates close to its maximum rate: $\mathrm{CMR}_{\mathrm{glc}}$ was $0.52 \pm 0.09 \mu \mathrm{mol} / \mathrm{g} /$ min. In line with this, we estimated from the present results that normal glucose concentrations in the brain are close to $1 \mu \mathrm{mol} / \mathrm{g}$ (much larger than $K_{\mathrm{M}}{ }^{\mathrm{HK}}$ ) at euglycaemia, in accordance to previous NMR or microdialysis measurements (reviewed in Barros et al. 2007). This concentration of glucose, which is mainly dependent on transport and consumption rates, is similar in both brain interstice and cytosol of brain cells, as suggested by comparison of diffusion properties of brain glucose and exclusively intracellular brain metabolites (Pfeuffer et al. 2000). However, ${ }^{1} \mathrm{H}$ NMR spectroscopy does not allow distinguishing the compartments where glucose is utilised. Nevertheless, the results by Pfeuffer et al. (2000) are in accordance with a fast and non-limiting transport across neuronal and glial cell membranes, where GLUT1 concentration largely exceeds that of the luminal and abluminal membranes of the endothelium (discussed in Simpson et al. 2007).

\section{Effects of anaesthesia on glucose homeostasis}

The cerebral metabolic rate of glucose consumption is regionally and activity-dependent (e.g.Sokoloff et al. 1977; Ueki et al. 1992; Linde et al. 1999). $\mathrm{CMR}_{\mathrm{glc}}$ increases upon somatosensorial stimulation under $\alpha$-chloralose anaesthesia (Ueki et al. 1992) and is reduced upon isoelectricity (Choi et al. 2002). Therefore, we further tested the capability of determining alterations of glucose uptake and consumption upon modulation of brain activity by anaesthesia conditions. In addition to $\alpha$-chloralose anaesthesia, thiopental and isoflurane were tested.

In the present metabolic models of brain glucose homeostasis, kinetic constants are apparent values because modulation effects, such as activity regulation of carriers (e.g. known for ATP, reviewed in Carruthers 1986) and carrier translocation to the membrane, were not taken in account. Therefore, inhibitory or stimulatory effects on glucose diffusion through the BBB will be reflected by alterations in $T_{\max }, K_{\mathrm{t}}$ or $K_{\mathrm{ii}}$, while modifications in glucose consumption will be depicted by modified value of $\mathrm{CMR}_{\mathrm{glc}}$ or $V_{\max }{ }_{\mathrm{HK}}$ (with $K_{\mathrm{M}}{ }^{\mathrm{HK}}$ set constant).

Barbiturates are effective depressors of the CNS with actions primarily on the $\mathrm{GABA}_{\mathrm{A}}$ receptor, but may also 
interact with glutamate receptors and voltage-gated ion channels. Along with reduction in synaptic activity, barbiturates are also known to depress energy metabolism. For example, they inhibit the oxidation of NADH in the respiratory chain (Aldridge and Parker 1960; Chance et al. 1963), inhibit glucose phosphorylation (Bielicki and Krieglstein 1976) and thus reduce $\mathrm{CMR}_{\mathrm{glc}}$ (Strang and Bachelard 1973; Sokoloff et al. 1977; Choi et al. 2002), and inhibit the capability of GLUT1 to transport glucose (Honkanen et al. 1995; Haspel et al. 1999; Stephenson et al. 2000). In accordance, our results showed a depression of both glucose transport at the $\mathrm{BBB}$ and glucose consumption in vivo, as indicated by reduced $T_{\max }$ and $\mathrm{CMR}_{\mathrm{glc}}$, compared with light $\alpha$-chloralose anaesthesia. Up to our knowledge, thiopental has not been widely employed in studies of brain glucose utilization, in contrast to pentobarbital. In a precedent study of glucose transport at steady-state (Lei et al. 2010), we determined that, relative to $\alpha$-chloralose, deep thiopental anaesthesia induces a $47 \%$ increase in $T_{\max } /$ $\mathrm{CMR}_{\text {glc }}$, which implies a larger reduction in glucose consumption than in transport, and leads to higher brain glucose content, as observed in the present study (Fig. 5). Sokoloff et al. (1977) observed a reduction in $\mathrm{CMR}_{\mathrm{glc}}$ under thiopental anaesthesia (at a lower dose than in the present study) compared with conscious rats, while a ${ }^{13} \mathrm{C}$ NMR spectroscopy study under deep pentobarbital anaesthesia reported $\mathrm{CMR}_{\mathrm{glc}}$ of $0.33-0.38 \mu \mathrm{mol} / \mathrm{g} / \mathrm{min}$ for the whole rat brain (Choi et al. 2002). At a lower dose of pentobarbital, $\mathrm{CMR}_{\mathrm{glc}}$ was found to range from 0.42 to $0.57 \mu \mathrm{mol} / \mathrm{g} / \mathrm{min}$ (Cunningham et al. 1986). Comparing directly different types of anaesthesia conditions, for example Linde et al. (1999) found $\mathrm{CMR}_{\mathrm{glc}}$ to be 0.66 and $0.33 \mu \mathrm{mol} / \mathrm{g} / \mathrm{min}$ in the conscious rat and under pentobarbital anaesthesia, respectively. In summary, the inhibition of glucose phosphorylation and concomitant reduction of $\mathrm{CMR}_{\text {glc }}$ under deep thiopental anaesthesia, in comparison to light $\alpha$-chloralose anaesthesia, unequivocally demonstrated the capability of detecting modulation of glucose metabolism with the present non-invasive strategy.

Brain glucose homeostasis is affected by halogenated ethers that are frequently used as anaesthetics, namely isoflurane (Noda et al. 2003) and enflurane (Myers and Shapiro 1979). Therefore, we finally assayed glucose transport and consumption kinetics under isoflurane anaesthesia and found similar kinetic parameters compared with $\alpha$-chloralose anaesthesia. However, $T_{\max }$ had a tendency to higher values and $K_{\mathrm{ii}}$ was generally lowered then when using $\alpha$-chloralose anaesthesia, resulting in higher brain glucose levels at steady-state (see Fig. 3d), which is a recurrent observation in many ${ }^{1} \mathrm{H}$ NMR spectroscopy studies in vivo under isoflurane at euglycaemia (e.g. Mlynárik et al. 2006, 2008; Kulak et al. 2010; Duarte et al. 2011b).

\section{Conclusion}

From the present results, we conclude that a four-state conformational model allows reliable determination of kinetics of both glucose uptake and consumption upon dynamic simultaneous measurement of plasma and brain glucose concentration changes. This method can therefore be an alternative to other non-invasive standard methods to determine glucose uptake and consumption that mostly relied on the utilization of isotope-enriched glucose or glucose analogs.

\section{Acknowledgements}

This work was supported by Swiss National Science Foundation (grant 122498) and by the Center d'Imagerie BioMédicale (CIBM) of the UNIL, UNIGE, HUG, CHUV, EPFL and the Leenaards and Jeantet Foundations. The authors are grateful to Sibylle Fallet for assistance in experiments under isoflurane. The authors have no conflicts of interest to declare.

\section{References}

Aldridge W. N. and Parker V. H. (1960) Barbiturates and oxidative phosphorylation. Biochem. J. 76, 47-56.

Archer D. P., Elphinstone M. G. and Pappius H. M. (1990) The effect of pentobarbital and isoflurane on glucose metabolism in thermally injured rat brain. J. Cereb. Blood Flow Metab. 10, 624-630.

Barros L. F., Bittner C. X., Loaiza A. and Porras O. H. (2007) A quantitative overview of glucose dynamics in the gliovascular unit. Glia 55, 1222-1237.

Bielicki L. and Krieglstein J. (1976) Inhibition of glucose phosphorylation in rat brain by thiopental. Naunyn. Schmiedebergs. Arch. Pharmacol. 293, 25-29.

Buschiazzo P. M., Terrell E. B. and Regen D. M. (1970) Sugar transport across the blood-brain barrier. Am. J. Physiol. 219, 1505-1513.

Carruthers A. (1986) ATP regulation of the human red cell sugar transporter. J. Biol. Chem. 261, 11028-11037.

Chance B., Williams G. R. and Hollunger G. (1963) Inhibition of electron and energy transfer in mitochondria. I. Effects of Amytal, thiopental, rotenone, progesterone, and methylene glycol. J. Biol. Chem. 238, 418-431.

Choi I. Y., Lei H. and Gruetter R. (2002) Effect of deep pentobarbital anesthesia on neurotransmitter metabolism in vivo: on the correlation of total glucose consumption with glutamatergic action. J. Cereb. Blood Flow Metab. 22, 1343-1351.

Cunningham V. J., Hargreaves R. J., Pelling D. and Moorhouse S. R. (1986) Regional blood-brain glucose transfer in the rat: a novel double-membrane kinetic analysis. J. Cereb. Blood Flow Metab. 6, 305-314.

Cuppoletti J. and Segel I. H. (1975) Kinetic analysis of active membrane transport systems: equations for net velocity and isotope exchange. J. Theor. Biol. 53, 125-144.

Duarte J. M. N., Carvalho R. A., Cunha R. A. and Gruetter R. (2009a) Caffeine consumption attenuates neurochemical modifications in the hippocampus of streptozotocin-induced diabetic rats. J. Neurochem. 111, 368-379.

Duarte J. M. N., Morgenthaler F. D., Lei H., Poitry-Yamate C. and Gruetter R. (2009b) Steady-state brain glucose transport kinetics re-evaluated with a four-state conformational model. Front. Neuroenergetics $\mathbf{1}, 6$. 
Duarte J. M. N., Lanz B. and Gruetter R. (2011a) Compartmentalised cerebral metabolism of $\left[1,6-{ }^{13} \mathrm{C}\right]$ glucose determined by in vivo ${ }^{13} \mathrm{C}$ NMR spectroscopy at 14.1 T. Front. Neuroenergetics 3, 3.

Duarte J. M. N., Kulak A., Gholam-Razaee M. M., Cuenod M. R., Gruetter R. and Do K. Q. (2011b) $N$-acetyl-cysteine normalizes neurochemical changes in the glutathione-deficient schizophrenia mouse model during development. Biol. Psychiatry. doi: 10.1016/ j.biopsych.2011.07.035.

Duarte J. M., Lei H., Mlynárik V. and Gruetter R. (2011c) The neurochemical profile quantified by in vivo ${ }^{1} \mathrm{H}$ NMR spectroscopy. Neuroimage 2011, 12; doi: 10.1016/j.biopsych.2011.07.035

Gjedde A. (1982) Calculation of cerebral glucose phosphorylation from brain uptake of glucose analogs in vivo: a re-examination. Brain Res. 257, 237-274.

Gjedde A. and Christensen O. (1984) Estimates of Michaelis-Menten constants for the two membranes of the brain endothelium. J. Cereb. Blood Flow Metab. 4, 241-249.

Gould G. W., Thomas H. M., Jess T. J. and Bell G. I. (1991) Expression of human glucose transporters in Xenopus oocytes: kinetic characterization and substrate specificities of the erythrocyte, liver, and brain isoforms. Biochemistry 30, 5139-5145.

de Graaf R. A., Pan J. W., Telang F., Lee J. H., Brown P., Novotny E. J., Hetherington H. P. and Rothman D. L. (2001) Differentiation of glucose transport in human brain gray and white matter. J. Cereb. Blood Flow Metab. 21, 483-492.

Grossbard L. and Schimke R. T. (1966) Multiple hexokinases of rat tissues. Purification and comparison of soluble forms. J. Biol. Chem., 241, 3546-3560.

Gruetter R. and Tkác I. (2000) Field mapping without reference scan using asymmetric echo-planar techniques. Magn. Reson. Med. 43, 319-323.

Gruetter R., Novotny E. J., Boulware S. D., Rothman D. L. and Shulman R. G. (1996) ${ }^{1} \mathrm{H}$ NMR studies of glucose transport in the human brain. J. Cereb. Blood Flow Metab. 16, 427-438.

Gruetter R., Ugurbil K. and Seaquist E. R. (1998) Steady-state cerebral glucose concentrations and transport in the human brain. J. Neurochem. 70, 397-408.

Gruetter R., Seaquist E. R. and Ugurbil K. (2001) A mathematical model of compartmentalized neurotransmitter metabolism in the human brain. Am. J. Physiol. Endocrinol. Metab. 281, E100E112.

Haspel H. C., Stephenson K. N., Davies-Hill T., El-Barbary A., Lobo J. F., Croxen R. L., Mougrabi W., Koehler-Stec E. M., Fenstermacher J. D. and Simpson I. A. (1999) Effects of barbiturates on facilitative glucose transporters are pharmacologically specific and isoform selective. J. Membr. Biol. 169, 45-53.

Honkanen R. A., McBath H., Kushmerick C., Callender G. E., Scarlata S. F., Fenstermacher J. D. and Haspel H. C. (1995) Barbiturates inhibit hexose transport in cultured mammalian cells and human erythrocytes and interact directly with purified GLUT-1. Biochemistry 34, 535-544.

Kulak A., Duarte J. M. N., Do K. Q. and Gruetter R. (2010) Neurochemical profile of the developing mouse cortex determined by in vivo ${ }^{1} \mathrm{H}$ NMR spectroscopy at $14.1 \mathrm{~T}$ and the effect of recurrent anaesthesia. J. Neurochem. 115, 1466-1477.

Lee W. J., Peterson D. R., Sukowski E. J. and Hawkins R. A. (1997) Glucose transport by isolated plasma membranes of the bovine blood-brain barrier. Am. J. Physiol. 272, C1552-C1557.

Lei H. and Gruetter R. (2006) Effect of chronic hypoglycaemia on glucose concentration and glycogen content in rat brain: A localized ${ }^{13} \mathrm{C}$ NMR study. J. Neurochem. 99, 260-268.

Lei H., Duarte J. M., Mlynarik V., Python A. and Gruetter R. (2010) Deep thiopental anesthesia alters steady-state glucose homeostasis but not the neurochemical profile of rat cortex. J. Neurosci. Res. 88, 413-419.

Linde R., Schmalbruch I. K., Paulson O. B. and Madsen P. L. (1999) The Kety-Schmidt technique for repeated measurements of global cerebral blood flow and metabolism in the conscious rat. Acta Physiol. Scand. 165, 395-401.

Lund-Andersen H. (1979) Transport of glucose from blood to brain. Physiol. Rev. 59, 305-352.

Mason G. F., Behar K. L., Rothman D. L. and Shulman R. G. (1992) NMR determination of intracerebral glucose concentration and transport kinetics in rat brain. J. Cereb. Blood Flow Metab. 12, 448-455.

Mlynárik V., Gambarota G., Frenkel H. and Gruetter R. (2006) Localized short-echo-time proton MR spectroscopy with full signalintensity acquisition. Magn. Reson. Med. 56, 965-970.

Mlynárik V., Cudalbu C., Xin L. and Gruetter R. (2008) 1H NMR spectroscopy of rat brain in vivo at 14.1Tesla: improvements in quantification of the neurochemical profile. J. Magn. Reson. 194, $163-168$.

Myers R. R. and Shapiro H. M. (1979) Local cerebral metabolism during enflurane anesthesia: identification of epileptogenic foci. Electroencephalogr. Clin. Neurophysiol. 47, 153-162.

Nakao Y., Itoh Y., Kuang T. Y., Cook M., Jehle J. and Sokoloff L. (2001) Effects of anesthesia on functional activation of cerebral blood flow and metabolism. Proc. Natl Acad. Sci. USA 98, 7593-7598.

Noda A., Takamatsu H., Minoshima S., Tsukada H. and Nishimura S. (2003) Determination of kinetic rate constants for 2- $\left[{ }^{18} \mathrm{~F}\right]$ fluoro-2deoxy-D-glucose and partition coefficient of water in conscious macaques and alterations in aging or anesthesia examined on parametric images with an anatomic standardization technique. J. Cereb. Blood Flow Metab. 23, 1441-1447.

Pardridge W. M., Boado R. J. and Farrell C. R. (1990) Brain-type glucose transporter (GLUT-1) is selectively localized to the bloodbrain barrier. Studies with quantitative western blotting and in situ hybridization. J. Biol. Chem. 265, 18035-18040.

Pfeuffer J., Tkác I. and Gruetter R. (2000) Extracellular-intracellular distribution of glucose and lactate in the rat brain assessed noninvasively by diffusion-weighted ${ }^{1} \mathrm{H}$ nuclear magnetic resonance spectroscopy in vivo. J. Cereb. Blood Flow Metab. 20, 736-746.

Schimke R. T. and Grossbard L. (1968) Studies on isozymes of hexokinase in animal tissues. Ann. N. Y. Acad. Sci. 151, 332-350.

Seaquist E. R., Damberg G. S., Tkac I. and Gruetter R. (2001) The effect of insulin on in vivo cerebral glucose concentrations and rates of glucose transport/metabolism in humans. Diabetes 50, 2203-2209.

Shestov A. A., Emir U. E., Kumar A., Henry P. G., Seaquist E. R. and Oz G. (2011) Simultaneous measurement of glucose transport and utilization in the human brain. Am. J. Physiol. Endocrinol. Metab. 301, E1040-E1049.

Shockley R. P. and LaManna J. C. (1988) Determination of rat cerebral cortical blood volume changes by capillary mean transit time analysis during hypoxia, hypercapnia and hyperventilation. Brain Res. 454, 170-178.

Siesjo B. K.. (1978) Utilisation of substrates by brain tissues. in Brain Energy Metabolism (Siesjo ed.), pp. 101-130. Wiley, New York.

Simpson I. A., Carruthers A. and Vannucci S. J. (2007) Supply and demand in cerebral energy metabolism: the role of nutrient transporters. J. Cereb. Blood Flow Metab. 27, 1766-1791.

Sokoloff L., Reivich M., Kennedy C., Des Rosiers M. H., Patlak C. S., Pettigrew K. D., Sakurada O. and Shinohara M. (1977) The $\left[{ }^{14} \mathrm{C}\right]$ deoxyglucose method for the measurement of local cerebral glucose utilization: theory, procedure, and normal values in the conscious and anesthetized albino rat. J. Neurochem. 28, 897916. 
Sprengers E. D., Koenderman A. H. and Staal G. E. (1983) Mitochondrial and cytosolic hexokinase from rat brain: one and the same enzyme? Biochim. Biophys. Acta 755, 112-118.

Stephenson K. N., Croxen R. L., El-Barbary A., Fenstermacher J. D. and Haspel H. C. (2000) Inhibition of glucose transport and direct interactions with type 1 facilitative glucose transporter (GLUT-1) by etomidate, ketamine, and propofol: a comparison with barbiturates. Biochem. Pharmacol. 60, 651-659.

Strang R. H. and Bachelard H. S. (1973) Rates of cerebral glucose utilization in rats anaesthetized with phenobarbitone. J. Neurochem. 20, 987-996.
Ueki M., Mies G. and Hossmann K. A. (1992) Effect of alpha-chloralose, halothane, pentobarbital and nitrous oxide anesthesia on metabolic coupling in somatosensory cortex of rat. Acta Anaesthesiol. Scand. 36, 318-322.

Weil-Malherbe H. and Bone A. D. (1951) Studies on hexokinase. 1. The hexokinase activity of rat-brain extracts. Biochem. J. 49, 339-347. 